\title{
DEVELOPMENT OF A PROCEDURE FOR DETERMINING THE PRE-FAILURE CONDITION OF THE AXLE BOXES OF RAILWAY ROLLING STOCK
}

\author{
Igor Martynov ${ }^{1}$, Juraj Gerlici ${ }^{2}$, Alyona Trufanova ${ }^{1}$, Vadim Petuhov ${ }^{1}$, Vadim Shovkun${ }^{1}$, Kateryna Kravchenko ${ }^{2, *}$ \\ ${ }^{1}$ Ukrainian State University of Railway Transport, Kharkiv, Ukraine \\ ${ }^{2}$ University of Zilina, Zilina, Slovakia \\ *E-mail of corresponding author: kateryna.kravchenko@fstroj.uniza.sk
}

\section{Resume}

It has been determined that the greatest risk of an error in determining the technical condition of the axle box unit in the so-called "zone of uncertainty" is in the impossibility of unambiguously assessing its technical condition. To solve this problem, a model is proposed in the form of an n-dimensional radius vector, which has a direction towards an increase in the probability of failure and a deterioration in its parameters' values. Such a model for determining the axle box unit's pre-failure condition will reduce the risk of errors in decision-making.

Available online: https://doi.org/10.26552/com.C.2022.1.B87-B93

\section{Article info}

Received 26 May 2021

Accepted 8 June 2021

Online 16 November 2021

\section{Keywords:}

axle box unit, control of technical condition, built-in control, ambiguity area, pre-failure condition, radius vector

ISSN $1335-4205$ (print version) ISSN 2585-7878 (online version)

\section{Introduction}

One of the main requirements for the railway rolling stock is to ensure transportation of goods and passengers [1-4]. One of the elements that directly affect the safety of cars' movement are the axle boxes with rolling bearings [4]. Failure of the axle box during the train's movement along the haul requires an immediate stop of the train and uncoupling of the faulty car. Untimely detection of the axle box unit's malfunction can lead to a fracture of the wheelset axle neck and then to the derailment of the car and an accident.

Control of the technical condition of axle boxes of cars on the railways is carried out in two ways: by car inspectors visually and tactilely and using the remote thermal control devices.

The appearance on the railways of a new generation of rolling stock [5] with various types of bearing assemblies led to difficulties in monitoring axle boxes' technical conditions.

Control of existing remote (non-contact) devices often leads to false alarms, which account for about $13 \%$ of all the train stops associated with the axle boxes' heating. There is a tendency towards increasing the number of such false alarms due to the increased number of cars equipped with various types of axle box housings, bearings and grease. As a result, this can cause unreasonable delays in trains' movement, disruptions to stability and rhythm of transportation, irrational expenditures of labor and material resources.

A qualitatively new development level of the axle box unit control system in operation has appeared by the built-in control means. Such control systems are used by leading manufacturers of bearing assemblies (SKF (Sweden), FAG (Germany), Timken (USA), etc.). The sensors' placement on the axle boxes is carried out promptly and officially and the technical condition is monitored. The data are obtained using wireless networks for making operational management decisions [6-9]. Similar studies are being conducted in Ukraine [10].

\section{Analysis of recent research}

The analysis of works devoted to studying, and axle box units' technical conditions shows that the problem of monitoring and diagnostics of the running gears of cars is very acute [11]. At the same time, a significant part of the problem is devoted to increasing the reliability of assessing the technical condition of the axle boxes [12-13]. Article [14] is devoted to studying the operating temperature regimes of axle boxes. Changes in design of the axle box units led to several questions. So, in the study [15], the testability of axle boxes of a new type is considered. Methods for early detection of malfunctions of axle boxes of cars are analyzed in the article [16]. 


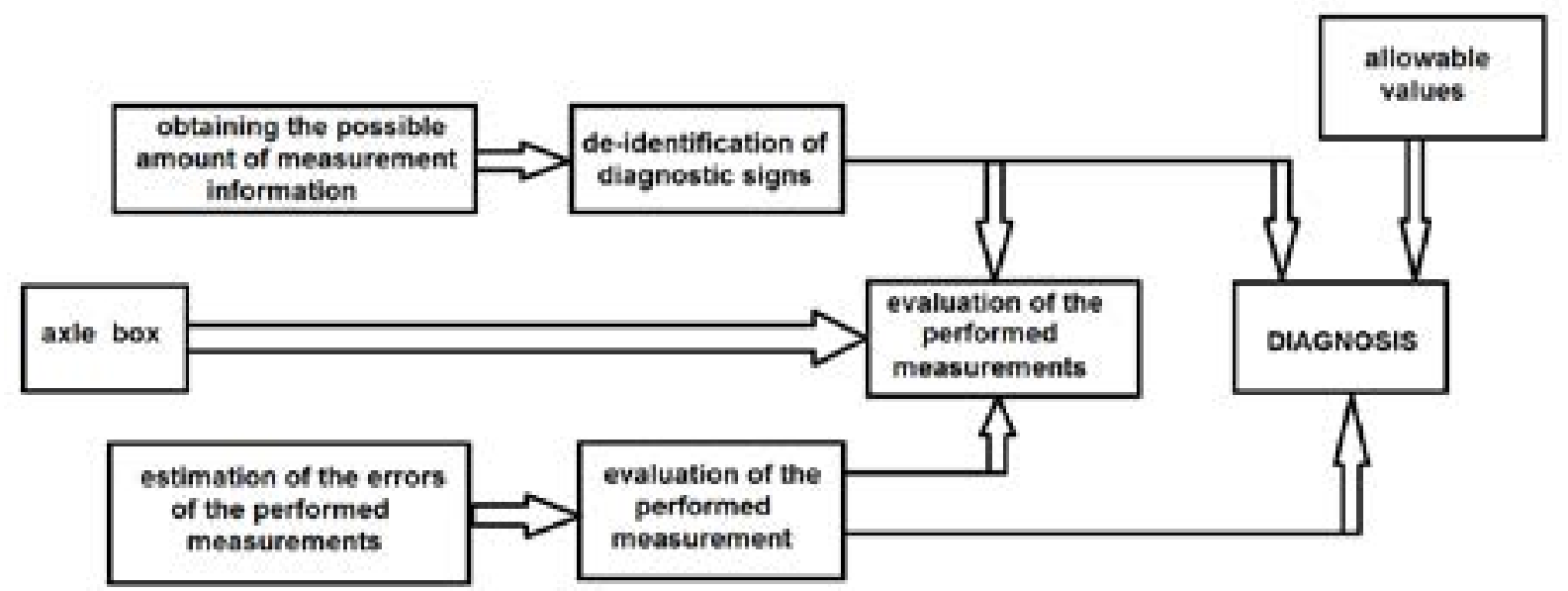

Figure 1 Diagram of the diagnostic procedure

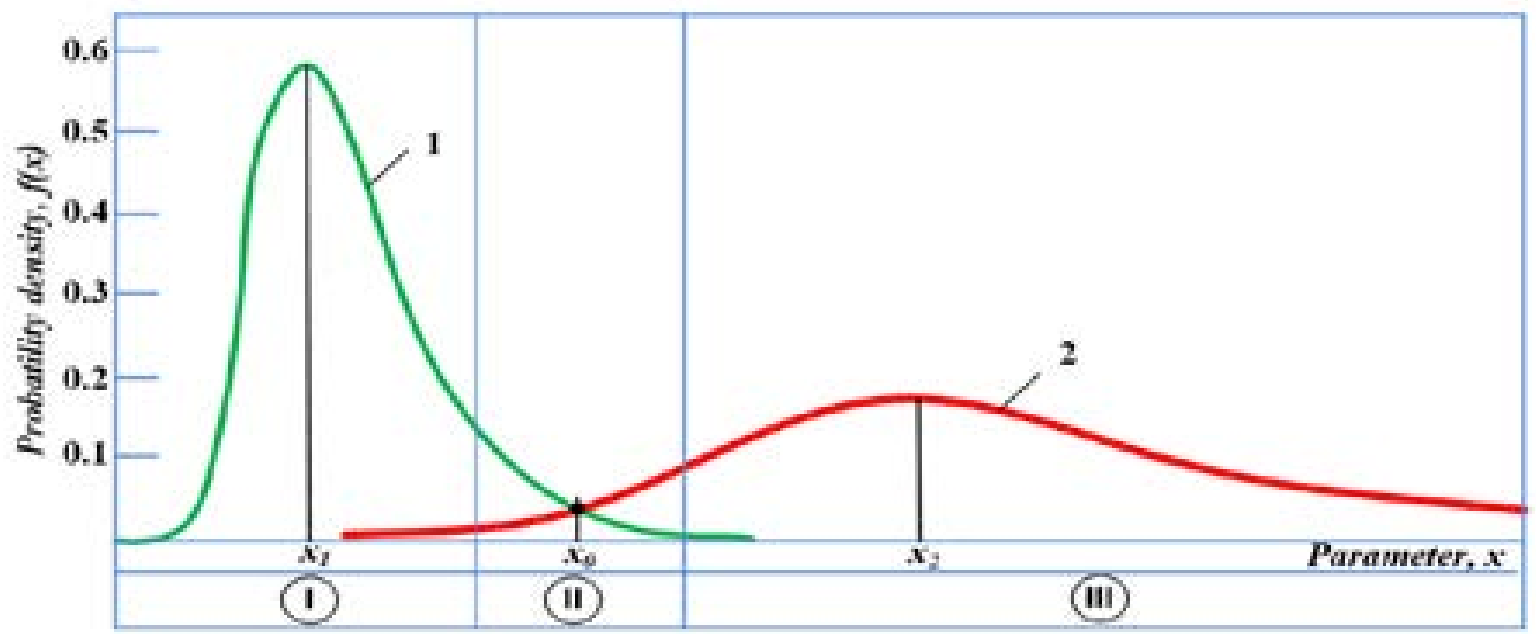

Figure 2 Graphic illustration of the "zone of uncertainty" when assessing the technical condition of the axle box unit

Obviously, the problem associated with the axle box unit failures' timely detection while the train is moving remains extremely urgent. Out of the field of vision of scientists are definitions of such concepts as "pre-failure state of the axle box", "the zone of the uncertainty of the technical state of the axle box", as well as the construction of a diagnostic model of the axle box.

\section{$3 \quad$ Material and methods}

According to the current regulatory documents [1718], the means of thermal control of the rolling stock give the operator three levels of alarm signals. The signal of the pre-emergency level "Alarm-0" does not require stopping the train. At the signal of the emergency level "Alarm-1," the train must be stopped for inspection at the nearest station. At the critical level "Alarm-2," an immediate stop and inspection of the specified car's axle boxes are required. Moreover, these critical levels may be different, depending on the operating conditions on different routes.

However, the axle boxes' technical condition (classification as serviceable or faulty) is always associated with the risk of a false alarm or a failure to detect a failure [19].

The diagnostic procedure for axle boxes consists of assessing their technical condition. The result of the work is to obtain a conclusion about the location of the object in one of the possible technical conditions. To do this, the following needs to be done:

1. Get the possible amount of information on directly measured values,

2. Estimate the errors of experimental information,

3. Perform the identification of the diagnostic features of the object using the diagnostic model,

4. Estimate the obtained identification errors for a given set of permissible parameters.

5. To assess the information content for a given set of directly measured values,

6. Make a diagnosis about the controlled object's technical condition at the time of this stage.

Figure 1 shows a schematic diagram of the diagnostic procedure.

In some cases, the diagnostic system is not able to unambiguously assess the technical condition of the axle boxes. In such cases, the diagnosis provides for such a concept as "zone of uncertainty". The "zone 


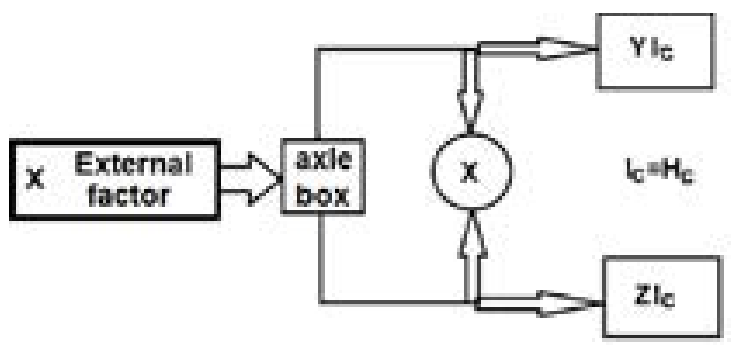

Figure 3 Diagnostic control method

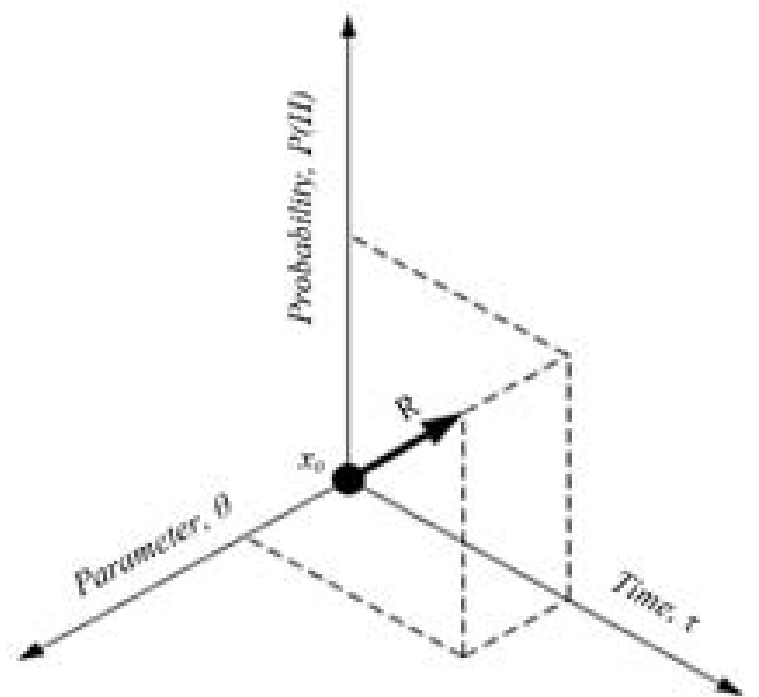

Figure 4 Radius vector of the technical condition of the axle box unit

of uncertainty" is clearly shown in Figure 2 - the distribution function of the probability density of the parameter: 1 - serviceable axle boxes; 2 - faulty axle boxes; I - zone of good condition; II - zone of uncertainty; III - fault zone.

This condition of the axle box occurs under the following conditions:

$\mathrm{X}_{1}-\mathrm{I}_{\mathrm{c}}=1$ - good condition,

$\mathrm{X}_{0}-\mathrm{I}_{\mathrm{c}}=\mathrm{H}_{\mathrm{c}}$ - zone of uncertainty,

$\mathrm{X}_{2}-\mathrm{H}_{\mathrm{c}}>\mathrm{I}_{\mathrm{c}}$ - faulty state,

where $\mathrm{I}_{\mathrm{c}}$ - good condition, $\mathrm{H}_{\mathrm{c}}$ - faulty condition.

The axle box's technical condition for control systems can be described by the following diagram (Figure 3).

Among the many operational states of the axle box, a pre-failure state can be distinguished, leading to a limit state and then to a transition to an inoperative state. The destruction of the bearing of the axle box is irreversible and, with the further operation, inevitably leads to a fracture of the journal of the wheelset axle.

It is necessary to determine at what technical condition of the axle box unit its further operation would lead to failure, i.e., when the failure has not yet occurred. Still, the likelihood of its occurrence is high.

Suppose that the axle assembly is operable at some arbitrary moment in time, but one of the diagnostic signs tends to approach the limiting (dangerous) value. That is, further operation of the axle box unit will lead to its failure. This state of the axle box unit is classified as the pre-failure.
A condition for detecting the pre-failure state is a change in the axle boxes' parameters (for example, heating temperature). The absence of an increase in the axle box units' heating temperature indicates that the pre-failure state has not occurred. If the probability of being in a faulty state $\mathrm{H}_{\mathrm{c}}$ is greater than the probability of $I_{c}$ being in a good state, the tendency for the parameters to deteriorate remains.

To identify the pre-failure state of the axle box unit, the following conditions must be met:

$\mathrm{X}_{1}=[\mathrm{Y}-\mathrm{YI}]=1$,

$\mathrm{X}_{0}=\left[\mathrm{Y}-\left(\mathrm{YI}_{\mathrm{c}}=\mathrm{H}_{\mathrm{c}}\right)\right] \neq 1$,

$\mathrm{X}_{2}=\left[\mathrm{Y}-\left(\mathrm{YI}_{\mathrm{c}}=\mathrm{H}_{\mathrm{c}}\right)\right]>\mathrm{ZI}_{\mathrm{c}}$.

The choice of methods and means of diagnostics, development of algorithms for finding a defect in the diagnostic object, presupposes a diagnostic model of the object. The diagnostic model is usually called a formal description of a given object, which characterizes it both in good working order and in a faulty state. The object description form can be any (analytical, tabular, vector, etc.).

To determine the axle box's pre-failure state, a diagnostic model is proposed in the form of an $n$-dimensional radius vector of the technical state of the axle box, which has a direction towards an increase in the probability of failure and a deterioration in the values of diagnostic parameters. 
Table 1 Temperature values of axle boxes on one side of the car

\begin{tabular}{ccccc}
\hline \multirow{2}{*}{ Axle box No. } & \multicolumn{4}{c}{ Axle box temperature $T\left[{ }^{\circ} \mathrm{C}\right]$ at the moment of time $\tau$ [min] } \\
\cline { 2 - 5 } & $\tau_{1}$ & $\tau_{2}$ & $\tau_{3}$ & 23.9 \\
2 & 15 & 17.2 & 20.8 & 29.9 \\
4 & 15 & 17.4 & 23.9 & 23.2 \\
6 & 15 & 17.1 & 22.5 & 23.2 \\
8 & 15 & 17.3 & 21.4 & 23.43 \\
\hline$T_{a v}^{*}$ & 15 & 17.2 & 21.57 & $\tau_{4}$ \\
\hline
\end{tabular}

For a more accurate determination of the prefailure condition as a vector value, it is advisable to use the "dynamic" recognition signs that reflect changes in parameters over time. In a particular case, the model for determining a pre-failure state has the form of a three-dimensional radius vector, where the abscissa corresponds to the value of time $\tau$, the ordinate is the diagnostic parameter - the temperature $\theta$, the applicate is the probability that the axle unit is in a faulty state $P(H)$ (Figure 4$)$. The value of the parameter at which $P(I)=P(H)$, is taken as the origin of coordinates, in Figure 4 that is the point $x_{0}$.

To create an algorithm for detecting the axle box's pre-failure state, it is required to determine the diagnostic signs (recognition signs) that characterize the technical condition of the axle box. When diagnosing an object, the area of possible values of the measured parameter (diagnostic sign) is in most cases divided into intervals and the presence of the parameter value in this interval is characteristic. In this regard, the quantitative determination of the measured parameter can be considered as a sign that takes several possible states [20].

During the movement, numerous external factors act on the axle unit, located in a certain conditional space of external influences $U$, which can take on values $\left(U_{1}, U_{2}, \ldots, U_{i} ; i=1 \ldots \infty\right)$. As a result of $U_{i}$ impact, the axle box unit of the car will be in the technical state $A_{i}$ from the space of possible technical states $A\left(A_{1}\right.$, $\left.A_{2}, \ldots, A_{i} ; i=1 \ldots \infty\right)$. Moreover, each technical state $A_{i}$ will correspond to a set of some diagnostic parameters $S$, which, in turn, will be characterized by a set of diagnostic features $K$. Feature $K_{j}$ has $m$ possible states: $k_{j 1}, k_{j 2}, \ldots, k_{j_{m}}$. If, as a result of diagnostics, it is revealed that for a given state of the axle box, the sign $K_{j}$ has the value $k_{j}$, this value is the implementation of the sign.

The diagnostic value of a feature is determined by the information entered by the feature into the system of states of the object being diagnosed. As the diagnostic weight of the implementation of the $K_{j}$ feature for the state $A_{i}$ of the object, take

$$
D_{A i}\left(k_{j L}\right)=\log _{2} \frac{P\left(A_{i} / k_{j_{L}}\right)}{P\left(A_{i}\right)}=\log _{2} \frac{P\left(k_{j L} / A_{i}\right)}{P\left(k_{j L}\right)}
$$

where:

$P\left(A_{i} / k_{j L}\right)$ is the probability of determining the state $A_{i}$, provided that the sign $K_{j}$ received the value $k_{j_{L}}$;
$P\left(A_{i}\right)$ - the prior probability of the diagnosis;

$P\left(k_{j_{L}} / A_{i}\right)$ is the probability of the $K_{j}$ feature hitting the $L$ interval for an object with the $A_{i}$ state;

$P\left(k_{j L}\right)$ - the probability of this interval's appearance for all the investigated control objects with different technical conditions.

The generally accepted indicator for monitoring the technical condition of axle boxes is their heating temperature. Moreover, the most informative sign for detecting the overheated axle boxes is the reduced temperature of the axle boxes on one side of the car to the average temperature of the axle boxes on the same side of the car $\theta_{i}=T_{i} / T_{a v}^{*}$, determined without the maximum temperature of one of the axle boxes [21].

\section{Results}

In 2015, operational tests of the built-in control system were carried out in Ukraine [8]. The purpose of the tests was to confirm the possibility of continuous monitoring of the axle boxes' technical condition by built-in means, as well as the wireless transmission of diagnostic information from the axle box to the ground modules of the control point when the train is moving.

An open-top car with axle boxes was used for the tests, having end fastening with an M110 nut. An onboard module was mounted in each axle box of the car on the end of the PY1 axle. The thermal sensor was fixed on the axle end face, which ensured the axle neck temperature control's maximum reliability.

The methodology program provided for the movement of an experimental gondola car at speeds of 20,30, 40 $\mathrm{km} / \mathrm{h}$ with the receipt of diagnostic information from the axle box and real data comparison.

The results obtained made it possible to simulate the heating level of the axle box units. Table 1 shows the axle boxes' temperatures on one side of the car, obtained from temperature measurements at the moments $\tau_{1}, \tau_{2}, \tau_{3}, \tau_{4}$.

The absolute temperature values of heating of all the axle boxes did not exceed the threshold values. Therefore, as mentioned earlier, to identify a faulty axle box unit, the sign "reduced temperature $\theta$ " was used.

If the axle boxes are in good working order, then when the car is moving, the ratio between the axle boxes' heating temperatures will be constant. An increase in 
Table 2 Sequence of differences in the reduced temperatures of the axle boxes

\begin{tabular}{ccccccccc}
\hline Axle box № & $\theta_{1}$ & $\theta_{2}$ & $\theta_{3}$ & $\theta_{4}$ & $\Delta \theta_{2-1}$ & $\Delta \theta_{3 \cdot 2}$ & $\Delta \theta_{4-3}$ \\
\hline 2 & 1.00 & 1.000 & 0.964 & 1.020 & 0.00 & -0.036 & 0.055 \\
4 & 1.00 & 1.012 & 1.108 & 1.276 & 0.012 & 0.097 & 0.168 \\
6 & 1.00 & 0.994 & 1.043 & 0.990 & -0.006 & 0.049 & -0.053 \\
8 & 1.00 & 1.006 & 0.992 & 0.990 & 0.006 & -0.014 & 0.002 \\
\hline & $3 \sigma$ & & & & 0.014 & 0.108 & 0.133 \\
\hline
\end{tabular}

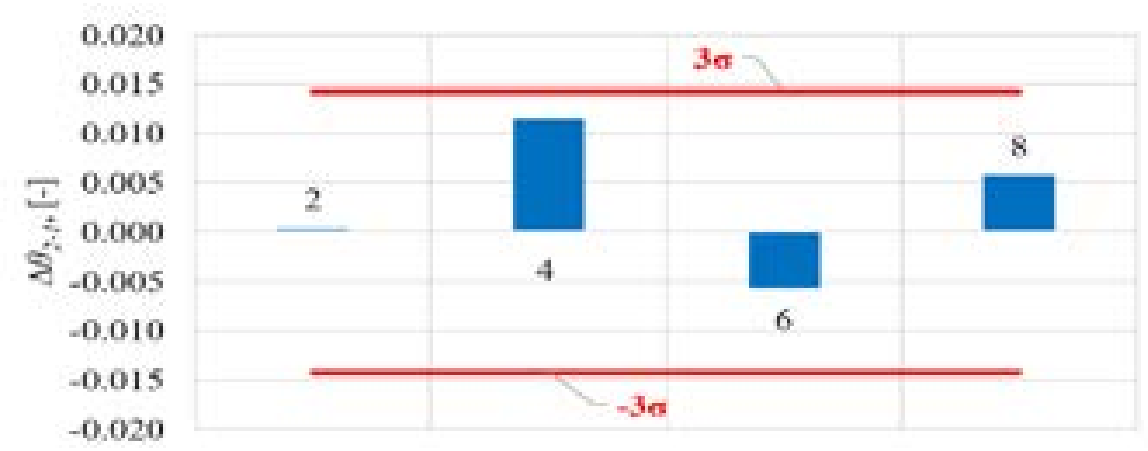

Figure 5 Sequence of differences in the reduced values of the temperatures of the axle boxes $\Delta \theta_{2-1}$

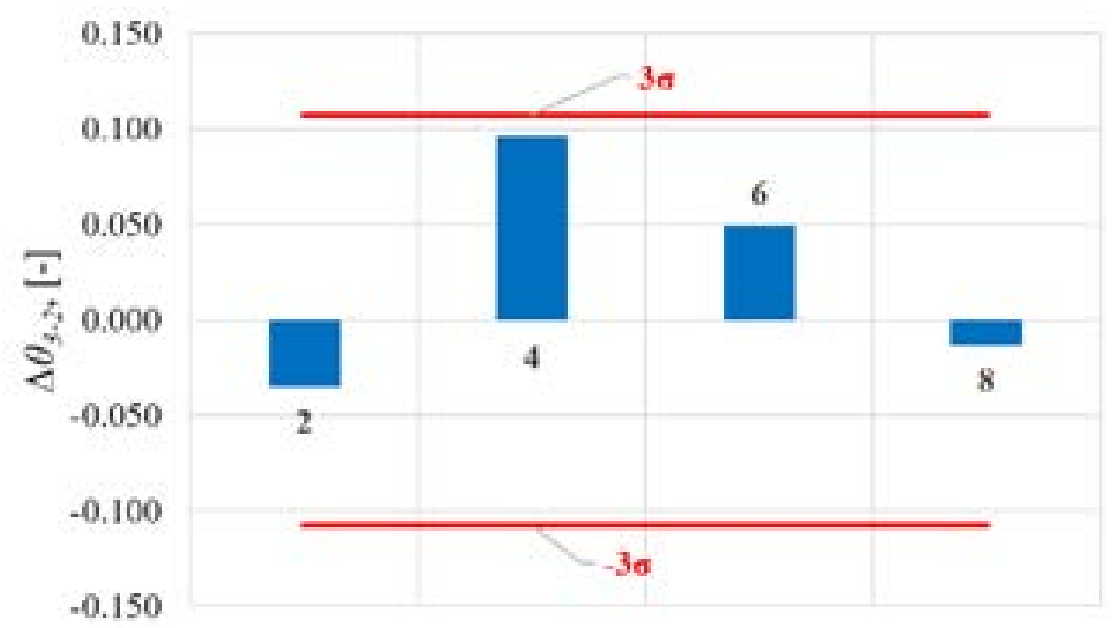

Figure 6 Sequence of differences in the reduced values of the temperatures of the axle boxes $\Delta \theta_{3-2}$

one of the axle boxes' reduced temperatures indicates development of an axle box defect.

Table 2 shows the sequence of differences in the reduced values of the temperatures of the axle boxes $\Delta \theta_{i}=\theta_{i, j+1}-\theta_{i, j}$ at times $\tau_{1}, \tau_{2}, \tau_{3}, \tau_{4}$.

To detect a pre-failure axle box, a threshold of significance of the reduced temperature increment is set, the excess of which indicates a malfunction. Assuming the normal distribution of increments as the threshold of significance, the boundaries of the confidence interval of values corresponding to a probability of 0.997 (the " $3 \sigma$ " rule) were taken.

$3 \sigma=3 \cdot\left(\sqrt{\frac{\sum_{i=1}^{n}\left(\theta_{i, j+1}-\theta_{i, j}\right)^{2}}{n-1}}\right)$.
These boundaries of the increment component equal to $\pm 3 \sigma$ are calculated according to Equation (3). The results are listed in Table 2 and shown in Figures 5-7 by solid lines.

In addition, Figures 5-7 show the sequence of differences in the reduced values of the axle boxes' temperatures at the moments of time $\tau_{2}, \tau_{3}, \tau_{4}$.

As shown in Figures 5-7, the temperature increment of the 4th axle box in the direction of travel tends to increase the difference in the reduced temperature compared to other axle boxes. It then goes beyond the confidence interval at time $\tau_{4}$, which indicates its prefailure state. 


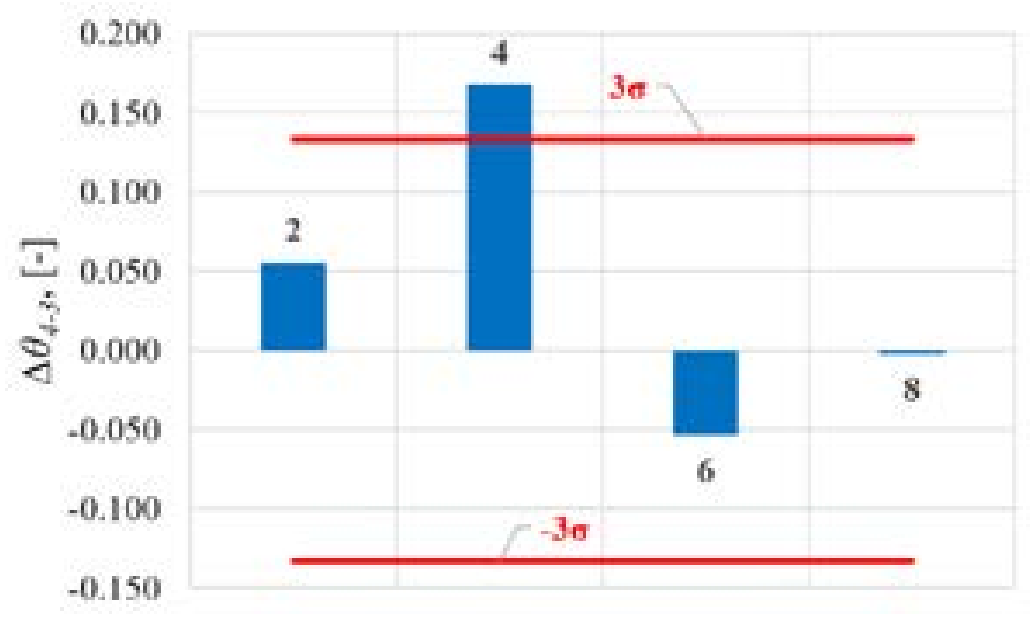

Figure 7 Sequence of differences in the reduced values of the temperatures of the axle boxes $\Delta \theta_{4-3}$

\section{Conclusions}

The task of modern diagnostic systems is early detection of faults and prevention of operation of the rolling stock with developing defects of critical units. Moreover, only the identification of the emergency axle box during the movement of the train no longer meets modern requirements.

The technical policy pursued by various railway administrations is aimed at the development and operation of the modern rolling stock with increased reliability. In operation, it leads to appearance of a variety of undercarriage designs with different types of bearings and grease. Therefore, it is not possible to unify the control algorithms, threshold values and accident rate criteria with existing thermal control systems for all the rolling stock units. Thus, the problem of control of axle boxes is already becoming urgent, which leading manufacturers solve, in particular, with help of the built-in control facilities, modernization of methods and algorithms for detecting faults. The greatest risk of an error in determining the technical condition of the axle box unit arises in the so-called "zone of uncertainty" due to the impossibility of unambiguously assessing its technical condition.

The built-in condition monitoring the technical condition of the axle boxes at this stage makes it possible to record not only the temperature, but also other parameters characterizing the condition of the axle box unit and the wheelset. In addition, taking into account the centralization of rolling stock control systems, the presence of powerful data processing centers and highspeed computer networks, it is possible to create an expert system to analyze the technical state of the unit and predict its resource.

However, the theoretical basis of such a control method is still under development and requires further work on its creation and development.

A procedure for detecting the pre-failure axle box unit, when its actual controlled parameters did not go beyond the permissible values, is proposed. The developed model for determining the pre-failure state and the procedure for identifying the pre-failure axle box unit would help to reduce the likelihood of making erroneous decisions about the train movement mode.

\section{References}

[1] DIZO, J., BLATNICKY, M., STEISUNAS, S., SKOCILASOVA, B. Assessment of a rail vehicle running with the damaged wheel on a ride comfort for passengers. MATEC Web of Conferences [online]. 2018, 157, 03004. ISSN 2261-236X. Available from: https://doi.org/10.1051/matecconf/201815703004

[2] DIZO, J., HARUSINEC, J., BLATNICKY, M. Computation of modal properties of two types of freight wagon bogie frames using the finite element method. Manufacturing Technology [online]. 2018, 18(2), p. 208-214. ISSN 1213-2489. Available from: https://doi.org/ 10.21062/ujep/79.2018/a/1213-2489/MT/18/2/208

[3] DIZO, J., BLATNICKY, M., HARUSINEC, J., FALENDYSH, A. Modification and analyses of structural properties of a goods wagon bogie frame. Diagnostyka [online]. 2019, 20(1), p. 41-48. ISSN 1641-6414. Available from: https://doi.org/10.29354/diag/99853

[4] STASTNIAK, P., KOHAR, R., SMETANKA, L. Dynamic analysis of force interactions in rolling bearings components. AIP Conference Proceedings [online]. 2019, 2198, 020018. ISSN 0094-243X. Available from: https:// doi.org/10.1063/1.5140879 
[5] MARTINOV, I. E. The results of temperature tests of the research axle boxes of freight wagon. Eastern-European Journal of Enterprise Technologies. 2004, 7(1), p. 66-69. ISSN 1729-3774.

[6] HODGE, V. J., O’KEEFE, S., WEEKS, M., MOULDS, A. Wireless sensor networks for condition monitoring in the railway industry: a survey. IEEE Transactions on Intelligent Transportation Systems [online]. 2015, 16(3/06), p. 1088-1106. ISSN 1524-9050. Available from: https://doi.org/10.1109/TITS.2014.2366512

[7] NAN, W., QINGFENG, M., BIN, Z., TONG, L., QINGHAI, M. Research on linear wireless sensor networks used for online monitoring of rolling bearing in freight train. Journal of Physics: Conference Series [online]. 2011, 305(1), 012024. ISSN 1742-6588. Available from: https://doi.org/10.1088/1742-6596/305/1/012024

[8] SCHOBEL, A., KARNER, J. Optimization potential in the positioning of hotbox detectors (in German). ETR. Eisenbahntechnische Rundschau. 2005, 12, p. 805-808. ISSN 0013-2845

[9] REASON, J. M., CHEN, H., CREPALDI, R., DURI, S. Intelligent telemetry for freight trains. Lecture Notes of the Institute for Computer Sciences, Social-Informatics and Telecommunications Engineering [online]. 2010, 35, p. 72-91. ISSN 1867-8211. Available from: https://doi.org/10.1007/978-3-642-12607-9_6

[10] MARTYNOV, I. E., PETUHOV, V. M. Full-scale testing of axle box troubleshooting station (in Russian). World of Transport and Transportation. 2013, 2, p. 180-182. ISSN 1992-3252.

[11] DIZO, J., BLATNICKY, M. Use of multibody system dynamics as a tool for rail vehicle behaviour diagnostics. Diagnostyka. 2016, 17(2), p. 9-16. ISSN 1641-6414.

[12] AI, S, WANG, W., WANG, Y., ZHAO, Z. Temperature rise of double-row tapered roller bearings analyzed with the thermal network method. Tribology International [online]. 2015, 87, p. 11-22. ISSN 0301-679X. Available from: https://doi.org/10.1016/j.triboint.2015.02.011

[13] TRESTMAN, E. E., LOZINSKIJ, S. N., OBRAZCOV, V. L. Automation of axle boxes control in trains (in Russian). Moscow: Transport, 1983.

[14] YAN, K., WANG, N., ZHAI, Q., ZHU, Y., ZHANG, J., NIU, Q. Theoretical and experimental investigation on the thermal characteristics of double-row tapered roller bearings of high speed locomotive. International Journal of Heat and Mass Transfer [online]. 2015, 84(May 2015). p. 1119-1130. ISSN 0017-9310. Available from: https://doi. org/10.1016/j.ijheatmasstransfer.2014.11.057

[15] MIRONOV, A. A., OBRAZTSOV, V. L., PAVLYUKOV, A. E., Traceability of rolling stock for thermal contactless diagnostics (in Russian). Journal Automation, Communication, Informatics. 2006, 11, p. 54-57. ISSN 0005-2329.

[16] PANKRATOV, L. V., CHISTYAKOV S. N. Monitoring of axle boxes heating (in Russian). Journal Automation, Communication, Informatics. 2008, 6, p. 23-24. ISSN 0005-2329.

[17] Instructions for the placement, installation and operation of automatic monitoring means of the technical condition of rolling stock during train movement (in Ukrainian) - TsV-TsSh-0053. Normative document of the State Administrative Administration of Railway Transport of Ukraine. Kyiv: Ukrzaliznytsya, 2003.

[18] Basic subsystem ASDK-B of automatic diagnostic control system ASDK (Automated dispatch control systems). Service technology (in Ukrainian). - TsSh-0037. Normative document of the State Administrative Administration of Railway Transport of Ukraine. Kyiv: Ukrzaliznytsya, 2005.

[19] BIRGER, I. A. Technical diagnostics (in Russian). 2 ed. URSS, 2019. ISBN 978-5-9710-6012-3.

[20] ALEKSEEVA, T. V., BABANSKAYA V. D., BASHTA T. M., ZAGREBELSKIJ, V. I., ZAJONCHKOVSKIJ, G. I., KOLOSOV S. V. Technical diagnostics of hydraulic drives (in Russian). Moskow: Mashinostroenie, 1989. ISBN 5-217-00489-4.

[21] PETUHOV, V. M. Analysis of temperature signs of identifying faulty axle boxes. Collection of Science Works of UkrDAZT. 2009, 107, p. 128-132. ISSN 1994-7852. 